\title{
Anger and Emotion Regulation Associated With Borderline and Antisocial Personality Features Within a Correctional Sample
}

Journal of Correctional Health Care 2020, Vol. 26(3) 215-226 (C) The Author(s) 2020 Article reuse guidelines: sagepub.com/journals-permissions DOI: I0.II77// 078345820937775 journals.sagepub.com/home/jcx

(SAGE

\section{Patrick T. McGonigal ${ }^{1,2}$ and Katherine L. Dixon-Gordon, PhD' ${ }^{(\mathbb{D}}$}

\begin{abstract}
Although diagnostically distinct, research indicates that antisocial personality disorder (ASPD) and borderline personality disorder (BPD) share common features, including anger impulses and emotion dysregulation. It is unclear, however, how these variables are expressed and experienced differentially. The current study sought to examine independent associations of forms of anger expression and emotion dysregulation among a sample of incarcerated males. Participants were 30 males incarcerated in a county jail who completed self-report measures of BPD and ASPD features, emotion dysregulation, and anger. Results revealed that when controlling for the co-occurrence of the other disorder, anger expression and emotion dysregulation were significantly associated with BPD. Difficulties engaging in goal-directed behavior were significantly associated with ASPD. BPD may confer unique clinical challenges among incarcerated samples.
\end{abstract}

\section{Keywords}

borderline personality disorder, antisocial personality disorder, emotion regulation, anger, correctional mental health

Although borderline personality disorder (BPD) and antisocial personality disorder (ASPD) are diagnostically distinct, they have considerable characteristic overlap and frequently co-occur, with rates of comorbidity of up to $26 \%$ (Becker et al., 2000). Specifically, the two disorders share diagnostic characteristics of anger, aggressive behavior, and difficulties regulating impulsivity (Fossati et al., 2004). Aside from diagnostic criteria, BPD and ASPD also share common negative outcomes including substance abuse, engagement in risky behaviors, and suicidality (McCloskey \& Ammerman, 2018). Although in the community the prevalence rate of BPD is $1 \%$ to $6 \%$ and ASPD

\footnotetext{
'Department of Psychological and Brain Sciences, University of Massachusetts, Amherst, MA, USA

${ }^{2}$ Department of Psychology, University of Nebraska, Lincoln, NE, USA
}

\section{Corresponding Author:}

Katherine L. Dixon-Gordon, PhD, Department of Psychological and Brain Sciences, University of Massachusetts Amherst, I35 Hicks Way, Amherst, MA 01003, USA.

Email: katiedg@gmail.com 
is $1 \%$ to $4 \%$ (Grant et al., 2008; Lenzenweger, 2008), a disproportionately high proportion of inmates present with BPD and ASPD (up to $30 \%$ to $60 \%$, respectively; Black et al., 2007; Gunter et al., 2007). Comorbid ASPD may be present in upward of $90 \%$ of inmates with BPD, whereas comorbid BPD may be present in about $44 \%$ of inmates with ASPD (Black et al., 2010; Wetterborg et al., 2015).

The management of ASPD and BPD is of utmost concern for correctional health care professionals as the disorders have substantial consequences within correctional settings and the community postrelease. Within the prison context, antisocial and borderline personality features are associated with frequent physical and verbal aggression and noncompliance, suicidality and self-injury, and poorer physical and emotional functioning (Black et al., 2007; Dixon-Gordon et al., 2012; Wang \& Diamond, 1999). Following release into the community, inmates with these disorders are significantly more likely to recidivate, violate parole, and face reincarceration (Abracen et al., 2014; Black et al., 2007; Shepherd et al., 2018). Additionally, these disorders bear a substantial burden to society more broadly, given their associations with recurrent inpatient hospitalizations, incarceration, unemployment, and overall mental health care (DeLisi et al., 2018; Salvador-Carulla et al., 2014). Properly screening, diagnosing, and treating these disorders are therefore essential for correctional professionals as mitigating their consequences may have substantial impacts on the well-being of the inmate as well as the community at large.

Problematic anger, irritability, and aggression are central components of both disorders and constitute a shared diagnostic criterion between BPD and ASPD (American Psychiatric Association, 2013; McCloskey \& Ammerman, 2018). Problematic anger is associated with poorer treatment response, quality of life, and greater symptom severity (Cassiello-Robbins \& Barlow, 2016). Inmates report more intense, frequent, and prolonged anger than nonincarcerated samples (Fernandez et al., 2014) and in isolation, anger is associated with a variety of negative outcomes among forensic populations, including recidivism (Çorapçığlu \& Erdoğan, 2004; Walters, 2007). Emotion regulation refers to the ability to influence the quality, intensity, and duration of an emotional response (Gross, 1998) in pursuit of one's goals (Gratz \& Roemer, 2004). Emotion regulation strategies play an important role in regulating anger experiences (Szasz et al., 2011). The relationship between BPD and emotion regulation difficulties has been well established in research literature (Aldao et al., 2010; Lynch et al., 2006; Lynch et al., 2007). Broadly, individuals with BPD report more intense negative emotions, have more variability in their experience of negative emotions, struggle to downregulate these emotions, and tend to avoid unwanted emotional experiences (Beblo et al., 2013; Bland et al., 2004; Lynch et al., 2006; Santangelo et al., 2014; Silvers et al., 2016). Evidence from studies investigating ASPD and emotion experiences suggests inmates with antisocial traits are less likely to demonstrate physiological reactivity to emotional stimuli (Herpertz et al., 2001) and blunted emotional processing (Verona et al., 2012). Both BPD and ASPD share the characteristic of anger dysregulation, yet the two represent different forms of personality pathology, thus negative emotions may be experienced and regulated differently depending on the primary pathology.

Despite their overlap, particularly in forensic settings, there is a lack of literature detailing the anger and emotion regulation difficulties unique to ASPD, BPD, or their co-occurrence. The current study sought to explore the linear relationship between BPD features, ASPD features, and their interaction on expressed and controlled anger, and emotion regulation difficulties in a correctional sample prior to receiving an anger management intervention. Because literature investigating the joint and independent relationships between these variables is limited, this analysis was exploratory. 


\section{Method}

\section{Participants}

Participants were 30 adult male inmates held in a county jail in western Massachusetts. All 30 inmates were scheduled to complete a mandated 12-week anger management training by personnel at the facility. Upon admission to the group intervention and prior to the group's initiation, inmates completed a battery of self-report measures described below. All participants provided written informed consent to participate in the study, and a subsample of 23 inmates consented to a review of their criminal record. All study procedures were approved by an institutional review board before data collection began.

\section{Measures}

BPD and ASPD features. The Personality Assessment Inventory (PAI; Morey, 1991) assesses several facets of dysfunction relating to personality attributes and personality disorders. The PAI has evidenced validity in forensic samples (Douglas et al., 2001) and is in fact a commonly used self-report personality measure in correctional research (see Gardner et al., 2015). Furthermore, the PAI corresponds to clinical diagnoses of BPD (Jacobo et al., 2007). For the purposes of this study, only the scales assessing borderline personality (PAI-BOR) and antisocial personality (PAI-ANT) were administered (possible ranges $=0$ to 72 , where higher scores indicate more personality pathology). The PAI-BOR's total score internal consistency for this study was adequate $(\alpha=.71)$; the PAI-ANT's total score internal consistency was high $(\alpha=.89)$.

Anger. The State-Trait Anger Expression Inventory-2 (STAXI-2; Spielberger, 1999) is a self-report measure that evaluates the severity of anger and has demonstrated strong validity in forensic samples (Etzler et al., 2014; Mela et al., 2008). A primary outcome in this study was the total Anger Index score where greater scores indicate greater anger expression, relative to control. The Anger Index is calculated based on the difference between the anger expression subscales and the anger control subscales (possible range $=0$ to 96 , where higher scores indicate less control over anger expressions; Spielberger, 1999). There are seven subscales on the STAXI-2 (possible ranges $=8$ to 32): Inward Anger Control, Outward Anger Control, Inward Anger Expression, Outward Anger Expression, Anger Temperament, Anger Reactivity, and Trait Anger. Each of these subscales demonstrated good internal consistency (all $\alpha>$.80).

Emotion regulation difficulties. The Difficulties with Emotion Regulation Scale (DERS; Gratz \& Roemer, 2004) is a 36-item measure that assesses overall emotion regulation difficulties (possible range $=36$ to 180 , where higher scores indicate more difficulties). The DERS demonstrates good test-retest reliability and construct and predictive validity and is significantly associated with objective measures of emotion regulation (Gratz \& Roemer, 2004; Gratz \& Tull, 2010). Subscales on the DERS include (1) nonacceptance of emotional responses, (2) lack of emotional awareness, (3) limited access to emotion regulation strategies, (4) difficulties engaging in goal-directed behavior, (5) impulse control difficulties, and (6) lack of emotional clarity. Internal consistency scores for the DERS for this study were strong $(\alpha=.88$ for total emotion dysregulation, $\alpha=.84$ for nonacceptance, $\alpha=.86$ for awareness, $\alpha=.76$ for strategies, $\alpha=.64$ for goal-directed behavior, $\alpha=.90$ for impulse control, $\alpha=.77$ for clarity).

\section{Data Analytic Plan}

We first examined participant characteristics in terms of average personality disorder features as measured by raw scores on the PAI to inspect the normality of data distribution (i.e., skewness, 
Table I. Demographic Characteristics of the Sample.

\begin{tabular}{|c|c|}
\hline Demographic Characteristics & $n(\%)$ or Mean (SD) \\
\hline \multicolumn{2}{|l|}{ Gender } \\
\hline Male & $30(100 \%)$ \\
\hline Age (years) & M29.87 (8.I) \\
\hline \multicolumn{2}{|l|}{ Race/ethnicity } \\
\hline Caucasian & $12(40.0 \%)$ \\
\hline African American & $5(16.7 \%)$ \\
\hline Hispanic/Latinx & $7(23.3 \%)$ \\
\hline Multiracial & $5(20.0 \%)$ \\
\hline \multicolumn{2}{|l|}{ Education (years) } \\
\hline Less than high school diploma & $2(6.7 \%)$ \\
\hline Some high school & $7(23.3 \%)$ \\
\hline High school graduate & $2(6.7 \%)$ \\
\hline GED & $9(30.0 \%)$ \\
\hline Technical school & I (3.3\%) \\
\hline Some college & $9(30.0 \%)$ \\
\hline \multicolumn{2}{|l|}{ Marital status } \\
\hline Single & $24(80.0 \%)$ \\
\hline Living with someone as married & $6(20.0 \%)$ \\
\hline Charged with $\geq$ I violent crime $^{a}$ & $16(69.6 \%)$ \\
\hline Clinical Characteristics & Mean (SD)/[Range] \\
\hline PAI BOR raw score total & $36.10(8.47) /[20$ to 53$]$ \\
\hline PAI ANT raw score total & $33.77(12.58) /[9$ to 57$]$ \\
\hline STAXI Al total & $45.10(14.21) /[13$ to 77$]$ \\
\hline DERS total & $87.28(18.55) /[58$ to $\mid 40]$ \\
\hline
\end{tabular}

Note. $N=30$. PAI = Personality Assessment Inventory; BOR = Borderline Personality subscale; ANT = Antisocial

Personality subscale; STAXI AI = State-Trait Anger Expression Index, Anger Index subscale; DERS = Difficulties in Emotion Regulation Scale.

${ }^{\text {a }}$ Frequency of violent crime is based on a subset of inmates who consented to criminal record review $(n=23)$.

kurtosis). We next conducted preliminary analyses, including examining descriptive statistics and zero-order correlations among personality features and emotion and anger variables. To address our primary analyses, we conducted a series of stepwise linear regressions to examine the effect of BPD, ASPD, and BPD $\times$ ASPD on anger and emotion dysregulation outcomes. Our sample size $(N=30)$ is expected to detect large effects $\left(f^{2}=.35\right)$ with adequate $(1-\beta \geq .80)$ power (Faul et al., 2007).

\section{Results}

\section{Characteristics of the Sample}

Forty percent of the sample was White, $23.3 \%$ identified as Hispanic/Latinx, $16.7 \%$ identified as African American/Black, and $20 \%$ identified as multiracial. The average age of the sample was $29.87(S D=8.12$; range $=20$ to 54$)$. Approximately $70 \%$ of the sample had completed at least a high school education. The majority of those who consented to a criminal record review were charged with at least one violent crime (69.6\%). The average trait anger in the sample fell at the 90th percentile relative to a nonpatient population, suggesting that they presented with fairly severe anger-related issues at intake (Spielberger, 1999). Compared to adult community samples' borderline personality and antisocial personality traits, this sample scored at the 96th percentile and 99th percentile, respectively, and compared to outpatient clinical samples at the 61 st and 91 st percentile, 
Table 2. Descriptive Statistics and Intercorrelations Among Personality Features, Anger, and Emotion Regulation.

\begin{tabular}{lcccccc}
\hline Variable & 1 & 2 & 3 & 4 & 5 & 6 \\
\hline I. Age & 1 & & & & & \\
2. Race (minority = I) & $-0.432^{*}$ & 1 & & & & \\
3. BPD & 0.007 & 0.034 & 1 & & & \\
4. ASPD & $-0.382^{*}$ & 0.012 & $0.579 * *$ & 1 & 1 & 1 \\
5. DERS total & 0.065 & 0.003 & $0.683^{* *}$ & $0.549 * *$ & 0.703 & ( \\
6. AXI & -0.026 & 0.181 & $0.485 * *$ & 0.346 & $85.10(14.21)$ \\
Mean (SD) or \% & $29.87(8.11)$ & $60 \%$ & $36.10(8.47)$ & $33.77(12.58)$ & $87.28(18.55)$ & 45.10 \\
\hline
\end{tabular}

Note. BPD = borderline personality disorder; ASPD = antisocial personality disorder; DERS = Difficulties in Emotion Regulation Scale; $\mathrm{AXI}=$ Anger Expression Index.

suggesting that this sample presented with substantially problematic personality disorder traits (Morey, 1991). Sample characteristics are presented in Table 1.

\section{Preliminary Analyses}

Descriptive statistics and intercorrelations are presented in Table 2. All variables exhibited relatively normal distribution properties (skewness and kurtosis $< \pm 2$ ). Of note, there were zero-order associations between both BPD and ASPD and emotion dysregulation on the DERS, whereas only BPD evidenced a zero-order association with the Anger Expression Index.

\section{Regression Analyses}

Results describing the relationship between personality features and dependent variables are shown in Tables 3 and 4. In Step 1 of these models predicting anger outcomes from the STAXI, results revealed that BPD features positively predicted overall anger expression, inward expressed anger, anger temperament, and trait anger after controlling for ASPD features. Yet ASPD was not significantly associated with any of these anger outcomes with BPD in the model. In Step 2 of these models, there were no significant interactions of ASPD with BPD.

In terms of emotion dysregulation, higher BPD features were associated with greater overall emotion dysregulation, nonacceptance of emotions, lack of regulation strategies, and difficulties with impulse control, controlling for ASPD. Higher ASPD features were associated with greater difficulties engaging in goal-directed behavior when controlling for BPD. In Step 2 of these models, there were no significant interactions of ASPD with BPD.

\section{Discussion}

The current study sought to investigate the differential anger and emotional experiences of inmates with ASPD and BPD features by controlling for comorbid personality traits. Although anger is an important diagnostic feature of both ASPD and BPD, the results of this study suggest that, at least within correctional samples, experiences of anger and emotion dysregulation may be more strongly reflective of BPD than of ASPD features. When controlling for ASPD features, BPD was significantly associated with several forms of anger experiences and domains of emotion regulation, namely overall anger expression, inward expressed anger, anger temperament, trait anger, overall emotion dysregulation, nonacceptance, lack of regulation strategies, and impulsivity. When controlling for BPD features, ASPD features were only significantly related to difficulties engaging in 


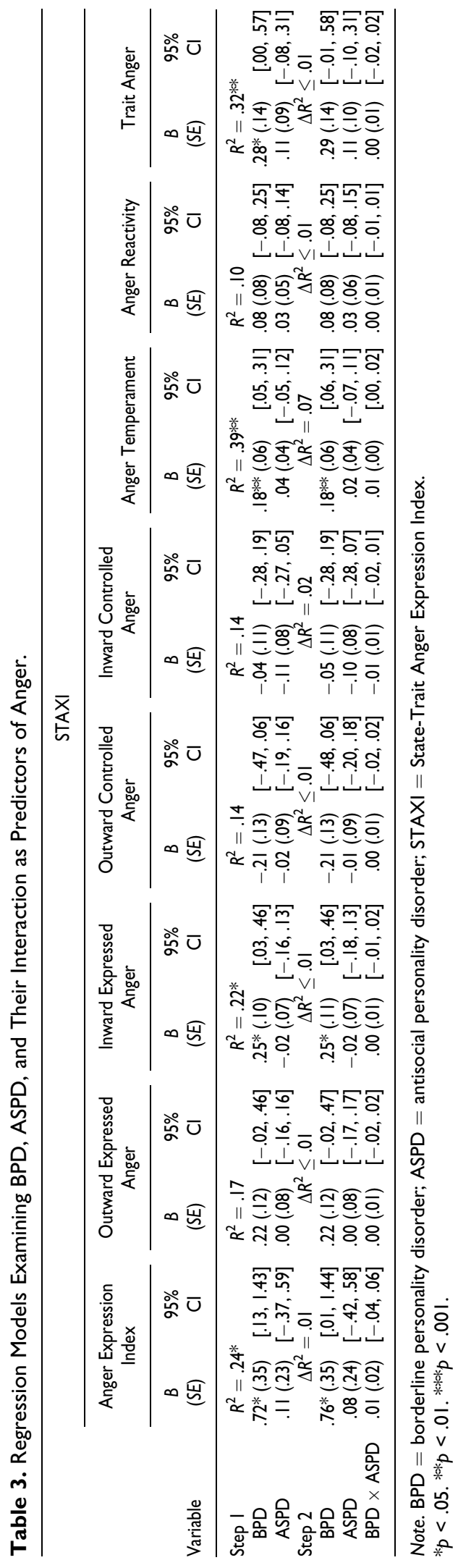




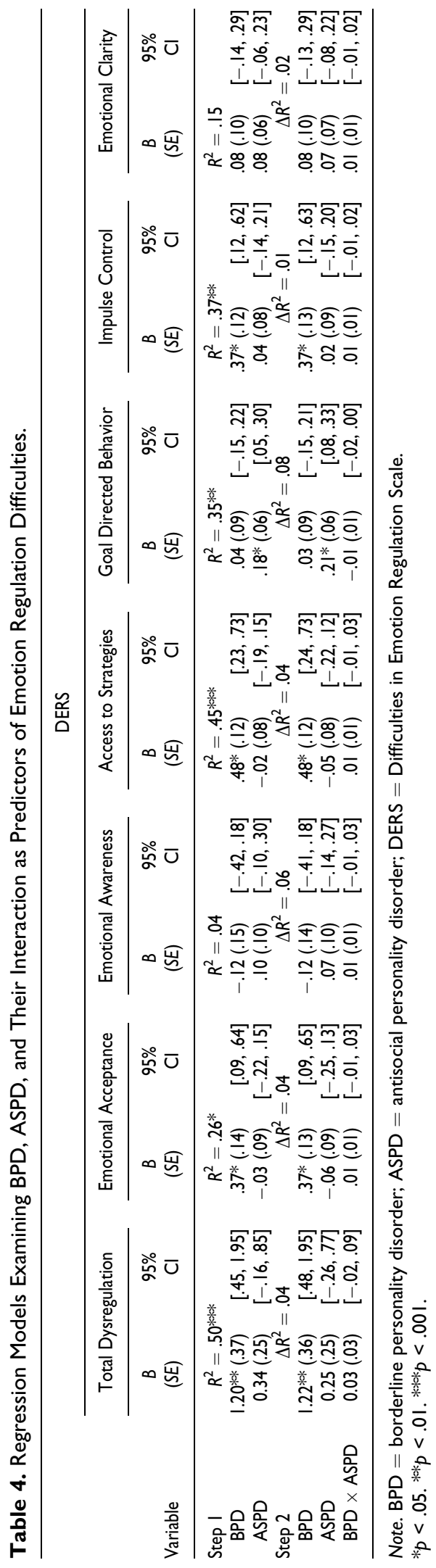


goal-directed behavior. These results are not to suggest that inmates with predominately ASPD features do not report anger, aggressive behavior, or emotion dysregulation; in fact, the items that compose the difficulties engaging in the goal-directed behavior scale may indicate more ruminative thought patterns (i.e., "when I'm upset, I have difficulty thinking about anything else"). This finding suggests that rumination may be salient within inmates with antisocial personality features. Nonetheless, our findings highlight that anger and emotion dysregulation may be particularly attributable to BPD traits.

Our study presents with several limitations that warrant mention. As mentioned above, our sample size was small, which may compromise the ability to detect effects and potentially increases the likelihood of committing a Type II error. Indeed, our power analysis indicated that we were only likely to detect large effects. Given the association between ASPD and generalized aggression and anger dysregulation (McCloskey \& Ammerman, 2018; Verona et al., 2012), this may reflect a Type II error or a relatively smaller effect size in the link between ASPD and anger outcomes among a sample with high levels on many of these variables. Future studies should replicate this analysis in a larger sample to investigate these effects in more detail. Conducting this study in a forensic setting was both a strength and limitation; our sample had elevated personality pathology features and anger symptoms, but it is unclear whether these results would generalize to other settings. Future research should investigate these issues in additional samples to promote external validity. The sample in the present study was entirely male. Given evidence suggesting differential expression of antisocial and borderline features across gender (Sher et al., 2019; Sher et al., 2015), future research should examine whether the obtained pattern of findings replicates to female inmates. Nevertheless, the present study supports the relevance and importance of screening for BPD in adult male offenders, especially given diagnostic biases regarding personality pathology that may be rooted in participant gender (Skodol \& Bender, 2003). In addition, not all of the inmates in our sample consented to a criminal record review, and thus we were unable to determine whether type of crime influenced results. Future research with larger samples may consider investigating whether these results differ across criminal histories. Finally, future research should investigate how these findings translate to a dimensional model of personality pathology, particularly regarding shared trait domains as classified by the DSM-5 alternative model of personality disorders (i.e., disinhibition, antagonism, negative affectivity; Morey et al., 2016). These limitations notwithstanding, we believe this study contributes to both forensic assessment and personality conceptualization literature.

These results have important treatment implications for clinicians treating individuals in forensic settings. Both BPD and ASPD patients may present with complex clinical issues and are often met with negative attitudes and frustration by clinicians (James \& Cowman, 2007; Reid \& Gacono, 2000; Treloar, 2009). These attitudes are especially common among clinicians in medium- and highsecurity settings (Beryl \& Völlm, 2018). Therefore, a clearer understanding of the unique roles of BPD and ASPD may offer a pathway to understand and target anger and emotion dysregulation more effectively in this population. Clinicians working with inmates who present with problematic anger and emotion dysregulation may consider prioritizing treatment targets related to BPD features rather than ASPD. Indeed, there is emerging data supporting the use of BPD treatments in forensic samples (Chapman \& Ivanoff, 2018; Ivanoff \& Marotta, 2018). These findings also suggest the importance of screening for both ASPD and BPD features as our sample scored high on these features, and the two have differential associations with anger and emotion regulation. For example, inmates exhibiting significant anger and dysregulation should be screened for both antisocial personality traits and borderline personality traits to ensure proper diagnosis and effective treatment dissemination.

\section{Declaration of Conflicting Interests}

The authors declared no potential conflicts of interest with respect to the research, authorship, and/or publication of this article. 


\section{Funding}

The authors received no financial support for the research, authorship, and/or publication of this article.

\section{ORCID iD}

Katherine L. Dixon-Gordon, PhD (D) https://orcid.org/0000-0002-6962-3121

\section{References}

Abracen, J., Langton, C. M., Looman, J., Gallo, A., Ferguson, M., Axford, M., \& Dickey, R. (2014). Mental health diagnoses and recidivism in paroled offenders. International Journal of Offender Therapy and Comparative Criminology, 58(7), 765-779. https://doi.org/10.1177/0306624X13485930

Aldao, A., Nolen-Hoeksema, S., \& Schweizer, S. (2010). Emotion-regulation strategies across psychopathology: A meta-analytic review. Clinical Psychology Review, 30(2), 217-237. https://doi.org/10.1016/j.cpr .2009 .11 .004

American Psychiatric Association. (2013). Diagnostic and statistical manual of mental disorders (5th ed.). https://doi.org/10.1176/appi.books.9780890425596

Beblo, T., Fernando, S., Kamper, P., Griepenstroh, J., Aschenbrenner, S., Pastuszak, A., Schlosser, N., \& Driessen, M. (2013). Increased attempts to suppress negative and positive emotions in borderline personality disorder. Psychiatry Research, 210(2), 505-509. https://doi.org/10.1016/j.psychres.2013.06.036

Becker, D. F., Grilo, C. M., Edell, W. S., \& McGlashan, T. H. (2000). Comorbidity of borderline personality disorder with other personality disorders in hospitalized adolescents and adults. American Journal of Psychiatry, 157(12), 2011-2016. https://doi.org/10.1176/appi.ajp.157.12.2011

Beryl, R., \& Völlm, B. (2018). Attitudes to personality disorder of staff working in high-security and mediumsecurity hospitals. Personality and Mental Health, 12(1), 25-37. https://doi.org/10.1002/pmh.1396

Black, D. W., Gunter, T. D., Allen, J., Blum, N., Arndt, S., Wenman, G., \& Sieleni, B. (2007). Borderline personality disorder in male and female offenders newly committed to prison. Comprehensive Psychiatry, 48(5), 400-405. https://doi.org/10.1016/j.comppsych.2007.04.006

Black, D. W., Gunter, T. D., Loveless, P., Allen, J., \& Sieleni, B. (2010). Antisocial personality disorder in incarcerated offenders: Psychiatric comorbidity and quality of life. Annals of Clinical Psychiatry, 22(2), $113-120$.

Bland, A. R., Williams, C. A., Scharer, K., \& Manning, S. (2004). Emotion processing in borderline personality disorders. Issues in Mental Health Nursing, 25(7), 655-672. https://doi.org/10.1080/016128404 90486692

Cassiello-Robbins, C., \& Barlow, D. H. (2016). Anger: The unrecognized emotion in emotional disorders. Clinical Psychology: Science and Practice, 23(1), 66-85. https://doi.org/10.1111/cpsp.12139

Chapman, A. L., \& Ivanoff, A. (2018). Forensic issues in borderline personality disorder. In B. Stanley \& A. S. New (Eds.), Primer on borderline personality disorder (pp. 403-420). Oxford University Press.

Çorapçıŏlu, A., \& Erdoğan, S. (2004). A cross-sectional study on expression of anger and factors associated with criminal recidivism in prisoners with prior offences. Forensic Science International, 140(2-3), 167-174. https://doi.org/10.1016/j.forsciint.2003.11.019

DeLisi, M., Reidy, D., Heirigs, M., Tostlebe, J., \& Vaughn, M. (2018). Psychopathic costs: A monetization study of the fiscal toll of psychopathy features among institutionalized delinquents. Journal of Criminal Psychology, 8(2), 112-124.

Dixon-Gordon, K. L., Harrison, N., \& Roesch, R. (2012). Non-suicidal self-injury within offender populations: A systematic review. International Journal of Forensic Mental Health, 11(1), 33-50. https://doi.org/10 $.1080 / 14999013.2012 .667513$

Douglas, K. S., Hart, S., \& Kropp, P. R. (2001). Validity of the Personality Assessment Inventory for forensic assessments. International Journal of Offender Therapy and Comparative Criminology, 45(2), 183-197. https://doi.org/10.1177/0306624X01452005 
Etzler, S. L., Rohrmann, S., \& Brandt, H. (2014). Validation of the STAXI-2: A study with prison inmates. Psychological Test and Assessment Modeling, 56(2), 178-194.

Faul, F., Erdfelder, E., Lang, A.-G., \& Buchner, A. (2007). G*Power 3: A flexible statistical power analysis program for the social, behavioral, and biomedical sciences. Behavior Research Methods, 39(2), 175-191. https://doi.org/10.3758/BF03193146

Fernandez, E., Arevalo, I., Vargas, R., \& Torralba, A. (2014). Norms for five parameters of anger: How do incarcerated adults differ from the community? International Journal of Forensic Mental Health, 13(1), 18-24. https://doi.org/10.1080/14999013.2014.889256

Fossati, A., Barratt, E., Caretta, I., Leonardi, B., Grazioli, F., \& Maffei, C. (2004). Predicting borderline and antisocial personality disorder features in nonclinical subjects using measures of impulsivity and aggressiveness. Psychiatry Research, 125(2), 161-170.

Gardner, B. O., Boccaccini, M. T., Bitting, B. S., \& Edens, J. F. (2015). Personality Assessment Inventory scores as predictors of misconduct, recidivism, and violence: A meta-analytic review. Psychological Assessment, 27(2), 534-544. https://doi.org/10.1037/pas0000065

Grant, B. F., Chou, S. P., Goldstein, R. B., Huang, B., Stinson, F. S., Saha, T. D., Smith, S. M., Dawson, D. A., Pulay, A. J., Pickering, R. P., \& Ruan, W. J. (2008). Prevalence, correlates, disability, and comorbidity of DSM-IV borderline personality disorder: Results from the wave 2 national epidemiologic survey on alcohol and related conditions. Journal of Clinical Psychiatry, 69(4), 533-545. https://doi.org/10.4088/jcp.v69n0404

Gratz, K. L., \& Roemer, L. (2004). Multidimensional assessment of emotion regulation and dysregulation: Development, factor structure, and initial validation of the Difficulties in Emotion Regulation Scale. Journal of Psychopathology and Behavioral Assessment, 26(1), 41-54. https://doi.org/10.1023/B:JOBA .0000007455 .08539 .94

Gratz, K. L., \& Tull, M. T. (2010). Emotion regulation as a mechanism of change in acceptance-and mindfulness-based treatments. In R. A. Baer (Ed.), Assessing mindfulness and acceptance processes in clients: Illuminating the theory and practice of change (pp. 107-133). New Harbinger Publications.

Gross, J. J. (1998). The emerging field of emotion regulation: An integrative review. Review of General Psychology, 2(3), 271-299. https://doi.org/10.1037/1089-2680.2.3.271

Gunter, T. D., Allen, J., \& Arndt, S. (2007). Borderline personality disorder in men and women offenders newly committed to prison. Comprehensive Psychiatry, 48, 400-405. https://doi.org/10.1016/j.comppsych.2007 .04 .006

Herpertz, S. C., Werth, U., Lukas, G., Qunaibi, M., Schuerkens, A., Kunert, H. J., Freese, R., Flesch, M., Mueller-Isberner, R., Osterheider, M., \& Sass, H. (2001). Emotion in criminal offenders with psychopathy and borderline personality disorder. Archives of General Psychiatry, 58(8), 737-745. https://doi.org/10 $.1001 /$ archpsyc.58.8.737

Ivanoff, A., \& Marotta, P. L. (2018). DBT in forensic settings. In M. A. Swales (Ed.), Oxford handbook of dialectical behaviour therapy (pp. 615-644). Oxford University Press. https://doi.org/10.1093/oxfordhb/ 9780198758723.013.14

Jacobo, M. C., Blais, M. A., Baity, M. R., \& Harley, R. (2007). Concurrent validity of the Personality Assessment Inventory Borderline scales in patients seeking dialectical behavior therapy. Journal of Personality Assessment, 88(1), 74-80. https://doi.org/10.1080/00223890709336837

James, P. D., \& Cowman, S. (2007). Psychiatric nurses' knowledge, experience and attitudes towards clients with borderline personality disorder. Journal of Psychiatric and Mental Health Nursing, 14(7), 670-678. https://doi.org/10.1111/j.1365-2850.2007.01157.x

Lenzenweger, M. F. (2008). Epidemiology of personality disorders. Psychiatric Clinics of North America, 31(3), 395-403. https://doi.org/10.1016/j.psc.2008.03.003

Lynch, T. R., Rosenthal, M. Z., Kosson, D. S., Cheavens, J. S., Lejuez, C. W., \& Blair, R. J. R. (2006). Heightened sensitivity to facial expressions of emotion in borderline personality disorder. Emotion, 6(4), 647-655. https://doi.org/10.1037/1528-3542.6.4.647 
Lynch, T. R., Trost, W. T., Salsman, N., \& Linehan, M. M. (2007). Dialectical behavior therapy for borderline personality disorder. Annual Review of Clinical Psychology, 3, 181-205. https://doi.org/10.1146/annurev .clinpsy.2.022305.095229

McCloskey, M. S., \& Ammerman, B. A. (2018). Suicidal behavior and aggression-related disorders. Current Opinion in Psychology, 22, 54-58. https://doi.org/10.1016/j.copsyc.2017.08.010

Mela, M., Balbuena, L., Duncan, C. R., Wong, S., Gu, D., Polvi, N., \& Gordon, A. (2008). The STAXI as a measure of inmate anger and a predictor of institutional offending. Journal of Forensic Psychiatry \& Psychology, 19(3), 396-406. https://doi.org/10.1080/14789940802164090

Morey, L. C. (1991). Personality Assessment Inventory: Professional manual. Psychological Assessment Resources.

Morey, L. C., Benson, K. T., \& Skodol, A. E. (2016). Relating DSM-5 section III personality traits to section II personality disorder diagnoses. Psychological Medicine, 46(3), 647-655. https://doi.org/10.1017/S0033 291715002226

Reid, W. H., \& Gacono, C. (2000). Treatment of antisocial personality, psychopathy, and other characterologic antisocial syndromes. Behavioral Sciences and the Law, 18(5), 647-662. https://doi.org/10.1002/1099 -0798(200010)18:5<647::aid-bs1407>3.0.co;2-o

Salvador-Carulla, L., Bendeck, M., Ferrer, M., Andión, O., Aragonès, E., \& Casas, M. (2014). Cost of borderline personality disorder in Catalonia (Spain). European Psychiatry, 29(8), 490-497. https://doi.org/10 .1016/j.eurpsy.2014.07.001

Santangelo, P., Bohus, M., \& Ebner-Priemer, U. W. (2014). Ecological momentary assessment in borderline personality disorder: A review of recent findings and methodological challenges. Journal of Personality Disorders, 28(4), 555-576. https://doi.org/10.1521/pedi_2012_26_067

Shepherd, S. M., Campbell, R. E., \& Ogloff, J. R. P. (2018). Psychopathy, antisocial personality disorder, and reconviction in an Australian sample of forensic patients. International Journal of Offender Therapy and Comparative Criminology, 62(3), 609-628. https://doi.org/10.1177/0306624X16653193

Sher, L., Rutter, S. B., New, A. S., Siever, L. J., \& Hazlett, E. A. (2019). Gender differences and similarities in aggression, suicidal behaviour, and psychiatric comorbidity in borderline personality disorder. Acta Psychiatrica Scandinavica, 139(2), 145-153. https://doi.org/10.1111/acps.12981

Sher, L., Siever, L. J., Goodman, M., McNamara, M., Hazlett, E. A., Koenigsberg, H. W., \& New, A. S. (2015). Gender differences in the clinical characteristics and psychiatric comorbidity in patients with antisocial personality disorder. Psychiatry Research, 229(3), 685-689. https://doi.org/10.1016/j.psychres .2015 .08 .022

Silvers, J. A., Hubbard, A. D., Biggs, E., Shu, J., Fertuck, E., Chaudhury, S., Grunebaum, M. F., Weber, J., Kober, H., Chesin, M., Brodsky, B. S., Koenigsberg, H., Ochsner, K. N., \& Stanley, B. (2016). Affective lability and difficulties with regulation are differentially associated with amygdala and prefrontal response in women with Borderline Personality Disorder. Psychiatry Research: Neuroimaging, 254, 74-82. https:// doi.org/10.1016/j.pscychresns.2016.06.009

Skodol, A. E., \& Bender, D. S. (2003). Why are women diagnosed borderline more than men? Psychiatric Quarterly, 74(4), 349-360. https://doi.org/10.1023/a:1026087410516

Spielberger, C. D. (1999). State-Trait Anger Expression Inventory-2 (STAXI-2): Professional Manual. Psychological Assessment Resources.

Szasz, P. L., Szentagotai, A., \& Hofmann, S. G. (2011). The effect of emotion regulation strategies on anger. Behaviour Research and Therapy, 49(2), 114-119. https://doi.org/10.1016/j.brat.2010.11.011

Treloar, A. J. C. (2009). A qualitative investigation of the clinician experience of working with borderline personality disorder. New Zealand Journal of Psychology, 38(2), 30-34.

Verona, E., Sprague, J., \& Sadeh, N. (2012). Inhibitory control and negative emotional processing in psychopathy and antisocial personality disorder. Journal of Abnormal Psychology, 121(2), 498-510. https://doi .org/10.1037/a0025308 
Walters, G. D. (2007). Predicting institutional adjustment with the lifestyle criminality screening form and the antisocial features and aggression scales of the PAI. Journal of Personality Assessment, 88(1), 99-105. https://doi.org/10.1080/00223890709336840

Wang, E. W., \& Diamond, P. M. (1999). Empirically identifying factors related to violence risk in corrections. Behavioral Sciences and the Law, 17(3), 377-389. https://doi.org/10.1002/(sici)1099-0798(199907/09)17:3 $<377$ ::aid-bs1351>3.0.co;2-m

Wetterborg, D., Långström, N., Andersson, G., \& Enebrink, P. (2015). Borderline personality disorder: Prevalence and psychiatric comorbidity among male offenders on probation in Sweden. Comprehensive Psychiatry, 62, 63-70. https://doi.org/10.1016/j.comppsych.2015.06.014 